16 a 18 de outubro de 2019 - Campinas | Brasil

\title{
AQUECIMENTO GLOBAL E SOLUÇÃO ATRAVÉS DO USO DE ENERGIA LIMPA
}

\section{Gabriela R. D. Lima*, Leonardo A. R. Pereira*, Thamara K. Cardoso, Diego C. Andrade, Juliano A. Bonacin.}

\section{Resumo}

O avanço da tecnologia trouxe muitos benefícios para a sociedade e em decorrência disso, graves problemas associados a emissão de gases de efeito estufa e um aquecimento global vem sendo observado. Uma alternativa para minimizar a emissão de gases estufa é o uso de hidrogênio e oxigênio para produção de energia. Esses gases podem ser obtidos a partir da eletrólise da água. Neste projeto, criou-se um pequeno carro movido a célula de combustível utilizando hidrogênio e oxigênio como combustíveis. Essa tecnologia minimiza os impactos ambientais e produz apenas vapor de água como subproduto.

\section{Palavras-chave:}

Eletrólise da água, hidrogênio, carrinho movido a hidrogênio.

\section{Introdução}

O aquecimento global é um fenômeno que vem acontecendo ao longo do tempo, que se intensificou a partir do século XX. Esse aumento de temperatura é devido a um crescente uso dos combustíveis fósseis, relacionado ao aumento da atividade industrial humana.

Mediante ao exposto foi elaborado um projeto que busca solucionar o problema da poluição causada especificamente pelos gases de efeito estufa, através da utilização do hidrogênio como principal fonte de energia para mover motores.

\section{Resultados e Discussão}

Para a realização da eletrólise, foram efetuados experimentos para determinar qual o melhor eletrólito e eletrodo a serem usados nos experimentos finais. Com isso, foram feitos testes usando diferentes eletrólitos: ácido acético, $\mathrm{NaCl}$ e $\mathrm{NaOH}$. O melhor resultado em relação a produção de gás hidrogênio foi a solução de $\mathrm{NaOH}$, pois o $\mathrm{NaCl}$ e o ácido acético apresentaram uma baixa produção de $\mathrm{H}_{2}$.

Após descobrir o melhor eletrólito foi empreendido outro experimento para verificar qual era a melhor concentração. Assim foram testadas soluções de $10 \%, 20 \%, 40 \%$ e $60 \% \mathrm{~m} / \mathrm{v}$. Dentre essas concentrações a que mostrou o melhor resultado foi a de $40 \%$.

Em seguida, foram realizados experimentos para identificar o melhor material para o eletrodo: grafeno, cobre e grafite. O grafite apresentou os melhores resultados, além de ser de fácil obtenção.

Por fim, foram montados dois sistemas para obtenção dos gases $\mathrm{O}_{2}$ e $\mathrm{H}_{2}$. No sistema $A$ foi utilizada uma fonte de energia elétrica ATX de $12 \mathrm{~V}$ e $300 \mathrm{~W}$ (Figura 1A), e no sistema $B$ foi utilizado um painel solar de $12 \mathrm{~V}$ e 3 Watts (Figura 1B). Após a obtenção dos gases, montou-se um carrinho movido a célula combustível (Figura 2).

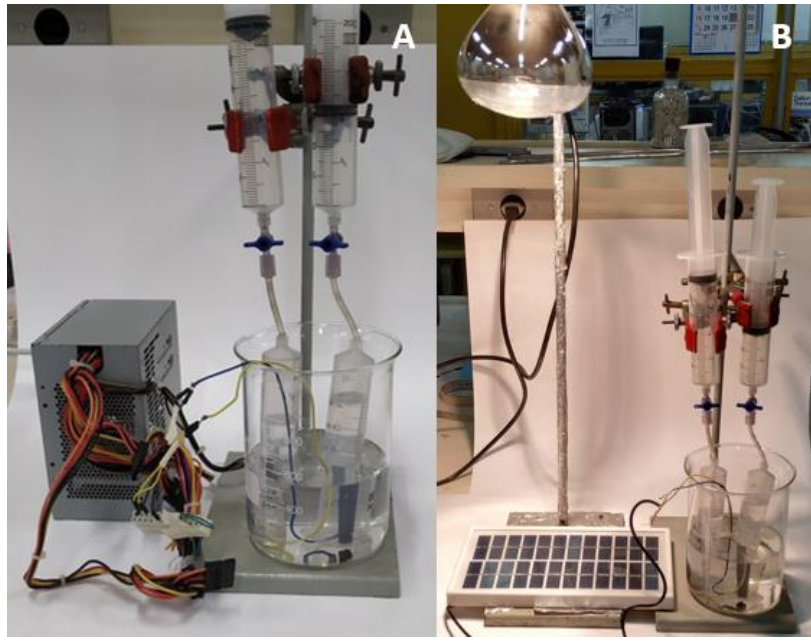

Figura 1. Sistemas para obtenção dos gases $\mathrm{H}_{2}$ e $\mathrm{O}_{2}$.

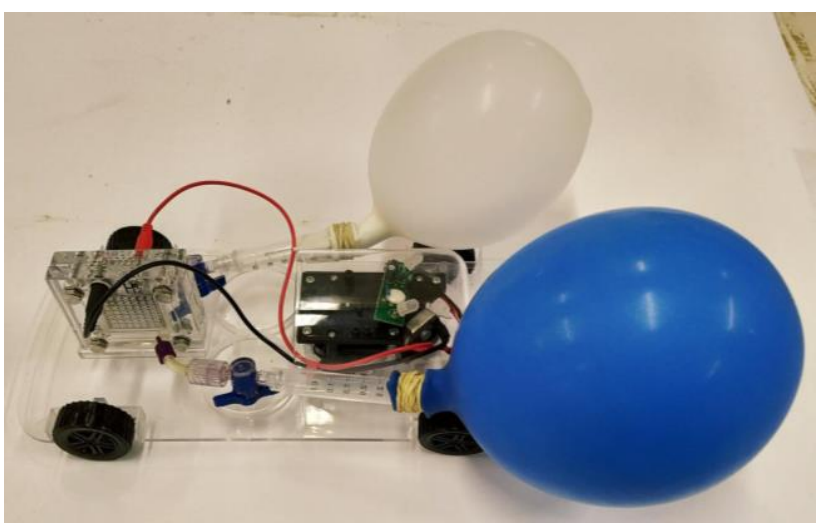

Figura 2. Carrinho movido a $\mathrm{H}_{2}$

\section{Conclusões}

Concluiu-se que é possível construir um carro movido a hidrogênio, embora o processo ainda possua obstáculos tecnológicos, como alto gasto de energia para geração dos gases e baixa eficiência da célula de combustível.

\section{Agradecimentos}

Agradecemos ao programa PIBIC Ensino Médio, da Pró Reitoria de Pesquisa da UNICAMP (Projeto FAEPEX № 3292018), e a Julia Merino pela ajuda. 